\title{
A sombra e a praça: análise de impacto do sombreamento de edificações altas em praças curitibanas
}

\author{
Shading Impact analysis from tall buildings over three public \\ spaces in Curitiba/PR
}

Jeanne Moro [a] (iD), Alessandro Filla Rosaneli [b] (iD)

Eduardo Krüger [a] (D), Silvana Camboim [b] [D]

[a] Universidade Tecnológica Federal do Paraná (UTFPR), Curitiba, PR, Brasil

[b] Universidade Federal do Paraná (UFPR), Curitiba, PR, Brasil

Como citar: Moro, J., Rosaneli, A., Krüger, E., \& Camboim, S. (2021). A sombra e a praça: análise de impacto do sombreamento de edificações altas em praças curitibanas. urbe. Revista Brasileira de Gestão Urbana, v. 13, e20200382. https://doi.org/10.1590/2175-3369.013.e20200382

\section{Resumo}

As sombras provenientes de edificações nas cidades são elementos determinantes na conformação de espaços públicos convidativos e adaptados às mudanças climáticas. Tendo-se em vista o aumento na altura das edificações definido na última atualização da legislação urbanística de Curitiba/PR, ocorrida em 2019, esse estudo tem por objetivo analisar o impacto do sombreamento proveniente de edificações do entorno a partir de simulações em três praças situadas em diferentes zonas não consolidadas ou em expansão, que permitem edificações com pelos menos seis pavimentos. 0 método, composto por diferentes etapas e utilizando-se de dados abertos, tem como resultado mapas para os solstícios de verão e inverno e equinócios. As análises demonstram que quando realizada a simulação considerando a altura das edificações com a aquisição de potencial construtivo, o impacto de sombreamento sobre os espaços públicos é considerável, principalmente no solstício de inverno. Sendo Curitiba um município caracterizado por um clima frio nesse momento do ano, um maior acesso solar nos espaços públicos pode ser recomendado. Advoga-se que o estudo do impacto de sombreamento proveniente das edificações lindeiras às praças seja uma possibilidade para delimitação de índices mais restritivos nos processos de planejamento urbano.

Palavras-chave: Sombreamento. Espaço público. Planejamento urbano.

\section{Abstract}

Buildings shading in cities are crucial elements in shaping inviting public spaces adapted to climate changing. In view of the increase in the buildings height defined in the last update of the urban legislation in the city of Curitiba/PR that took place in 2019, this study aims to analyze the impact of shading from surrounding buildings from simulations in three squares located in different zonings not consolidated or expanding which

JM é arquiteta e urbanista, doutora em Engenharia Civil, e-mail: jeannemoro@gmail.com

AFR é arquiteto e urbanista, doutor em Arquitetura e Urbanismo, e-mail: alefilla@yahoo.com

EK é engenheiro civil, doutor em Arquitetura, e-mail: ekruger@utfpr.edu.br

SC é engenheira cartógrafa, doutora em Ciências Geodésicas, e-mail: silvanacamboim@gmail.com 
allow buildings with at least six floors. The method composed of different steps from open data, results in different maps for the summer and winter solstices, and equinoxes. The analyzes demonstrate that when the simulation is carried out considering the buildings height with the acquisition of constructive potential, the shading impact on public spaces is considerable, especially in the winter solstice. Considering Curitiba as a city characterized by cold at that time of the year, ample solar access in public spaces can be recommended. It is argued that the study of the impact of buildings shading is a possibility for delimiting more restrictive indices in urban planning processes.

Keywords: Shading. Public space. Urban planning.

\section{Introdução}

A presença de praças na cidade contemporânea tem sido motivo de variado questionamento. De um lado, a gestão e o planejamento urbano têm demonstrado dificuldades em colocar o tema do espaço público em destaque e, assim, as já poucas praças existentes, ou áreas dedicadas a futuras praças, acabam sendo tratadas como reserva de terra urbana para os mais variados fins, como escolas, creches, unidades de pronto atendimento, etc. De outro, os cada vez mais raros usuários têm dificuldades de terem suas aspirações atendidas, uma vez que esses espaços não conseguem traduzir as dinâmicas contemporâneas da própria sociedade que as abrigam. Dessa forma, é usual observar situações que dificultam a atração e permanência de frequentadores: inexistência ou inadequação de mobiliário urbano, falta de manutenção, dentre tantos outros. É comum observar, portanto, que muitas praças não têm nenhuma utilização durante horas, às vezes, dias. Mesmo assim, compreende-se que tais espaços públicos são especialmente importantes para que uma enorme gama de atividades humanas possa se realizar no ambiente urbano, enriquecendo a vida pública. Ao mesmo tempo, sua função ambiental não cessa pelo seu não uso, tornando-as importantes mecanismos de mitigação de impactos ambientais, pelas áreas permeáveis e pelo sombreamento.

Portanto, o objetivo deste estudo é analisar um dos aspectos poucos estudados para que uma praça possa ser melhor aproveitada, especialmente em relação a sua adequação às condicionantes climáticas locais, que no caso de Curitiba, capital do Estado do Paraná, deveriam ser especialmente trabalhadas. Nesse sentido, o sombreamento a partir de edifícios lindeiros é o foco da pesquisa ora apresentada e, para tanto, estrutura-se o texto em três partes: na primeira, estabelece-se uma discussão sobre marcos conceituais acerca de pesquisas que tratam da importância do estudo do sombreamento em ambientes urbanos. Na segunda, expõe-se a metodologia empregada para se estudar as praças em Curitiba. Por fim, apresentam-se os resultados na seção seguinte. Com essa perspectiva pretende-se colaborar para que o espaço público possa assumir renovada dimensão nos processos de planejamento e gestão urbana.

\section{Sombras nas cidades}

De acordo com Instituto Brasileiro de Geografia e Estatística (IBGE, 2010), o Brasil vem em crescente urbanização desde a década de 1940, atingindo aproximadamente 85\% de taxa de urbanizada em 2010. Segundo Lodoba \& De Angelis (2005) tal processo tem inúmeras consequências no ambiente físico e na qualidade de vida de seus moradores. No tocante às questões ambientais, são inúmeros e de diferentes amplitudes os impactos que podem ocorrer, em virtude da interdependência dos múltiplos subsistemas que coexistem numa cidade. Assim, mudanças no uso e cobertura do solo, poluição das águas e de terrenos, empobrecimento da paisagem urbana, dentre tantos, acabam tornando a vida nas cidades cada vez mais desafiadora. Além disso, estudos tem analisado os problemas de saúde pública causados pelo desconforto térmico local, proveniente das mudanças nos ventos e do sombreamento prolongado, que afeta também os espaços públicos como as ruas, praças e parques (Correia Filho et al.., 2019).

Segundo Wall \& Waterman (2012), as elevadas alturas das edificações, oriunda das possibilidades da verticalização, influenciam o equilíbrio da razão entre a altura e a largura das ruas, afetam a quantidade de 
sol incidente, impactam no desenvolvimento dos padrões de uso do solo e também alteram a linha do horizonte, fatos que, decididamente, afetam a paisagem urbana.

Gehl (2011) afirma que tanto a cidade como o planejamento urbano podem melhorar ou piorar o clima local alterando, assim, a situação espacial. Segundo esse autor, o microclima adequado em espaços livres ou em rotas de pedestre é crucial para o conforto externo e para oferecer oportunidades de permanência e uso de espaços ao ar livre. Segundo Macedo (1995), na região Sul do Brasil, o ideal seria a presença de espaços com sombreamento moderado em dias de verão e a insolação plena em dias de inverno. Também Capeluto et al. (2006) salientam a importância de áreas ensolaradas nos espaços públicos, especialmente no inverno. Embora o sombreamento seja muito importante no verão, deve-se considerar principalmente a exposição solar de inverno, pois o sombreamento no verão pode ser alcançado por soluções dinâmicas, como árvores decíduas ou por estruturas leves que podem ser dobradas ou retiradas nos períodos mais frios. Por outro lado, ainda segundo os autores, o acesso solar não pode ser alcançado no inverno se os edifícios no entorno bloquearem completamente o sol'1.

Algumas pesquisas foram desenvolvidas considerando o sombreamento proveniente de edificações como fator impactante do uso e permanência nos espaços livres, em sua maioria relacionados ao conforto térmico. Dentre eles pode-se citar Huang et al. (2015), Lin et al. (2010; 2013), Martinelli et al. (2015) e Piaskowy \& Krüger (2016; 2017).

Huang et al. (2015) afirmam que o sombreamento pode bloquear a radiação solar e influenciar significantemente os ambientes térmicos. A pesquisa, realizada através de medições dos parâmetros térmicos no sol e na sombra e observações, através de vídeos em duas estações do ano (quente e fria) para determinar o número e atividades dos usuários, demonstrou que, durante a estação fria, o número de usuários foi maior e que, durante a estação quente, o número de usuários diminuiu quando as temperaturas e o índice de temperatura equivalente fisiológica (PET) ficaram mais altos. Ademais, durante a estação fria, o número de usuários aumentou quando a temperatura subiu também.

Lin et al. (2013) concluíram no mesmo sentido, uma vez que em áreas com acesso solar em tempo integral, sem sombras, o número de visitantes aumenta em estações frias do ano, enquanto o número de visitantes diminui durante as estações quentes.

O estudo de Martinelli et al. (2015), que discute a relação entre padrões de sombra diários e presença de usuários e conforto térmico durante o verão numa praça, observando o descanso em bancos, recomenda que, ainda na fase de concepção dos espaços públicos, é importante realizar análises de sombreamento. Além disso, indicam que o uso de dispositivos de sombreamento deve estar em conformidade com os usos do local, propiciando sombras durante os momentos de maior necessidade.

Outra vertente de estudos sobre impacto do sombreamento proveniente de edificações foram direcionados à compreensão da sua relação com o planejamento urbano, especialmente Gonçalves et al. (2013), Castro Perez (2013) e Mendes et al. (2015). Mas aqueles que procuram apresentar métodos de quantificação do sombreamento e acesso solar em ambientes públicos abertos datam de longo data em sua maioria, tais como: Yezioro \& Shaviv (1994), Leveratto (2002), Bourbia \& Awbi (2004), Yezioro et al. (2006), Ribeiro et al. (2010), Waldron \& Salazar (2013), Miranda et al. (2017) e Moro et al. (2019).

Algumas grandes cidades criaram normativas e métodos de análise para auxiliar no estudo de possíveis áreas impactadas, como São Francisco, Boston e Nova Iorque nos Estados Unidos, além de algumas cidades litorâneas no Brasil, como Rio de Janeiro e Salvador. Também a Lei Federal no 10.257 (Brasil, 2001), prevê o Estudo de Impacto de Vizinhança (EIV), incluindo como tópico de análise o conforto ambiental que engloba os estudos de ventilação, iluminação e poluição sonora e atmosférica nos centros urbanos (Schvarsberg et al., 2016). No entanto, outras metrópoles brasileiras ainda não incorporaram em sua dinâmica estes estudos, como São Paulo e Curitiba/PR. No caso do município de Curitiba, ainda que

\footnotetext{
1 Os mesmos autores concluíram que, para a Latitude $32^{\circ} \mathrm{N}$, pelo menos um terço da área da praça seja exposta ao sol de inverno durante cinco horas diárias, gerando uma área insolada suficientemente extensa para localizar diferentes funções, como áreas para se sentar e áreas de jogos. Em geral, recomendam que, para as latitudes entre $26^{\circ}$ e $34^{\circ}$, a altura dos edifícios de entorno deveria ser inferior a $1 / 3$ de sua largura (Yezioro et al., 2006).
} 
não haja o EIV regulamentado, o Relatório Ambiental Prévio (RAP) é utilizado como instrumento para essa finalidade para regular atividades e/ou empreendimentos tais como projetos de parcelamento de solo, empreendimentos comerciais e de serviços (Hoshino et al., 2014).

Segundo Rosaneli (2019), em cada momento da história e em distintos arranjos sociais, moldou-se uma distinta natureza para o espaço público. Mas a sua característica essencial, de local de encontros que conformam as relações socais, indica que sua materialidade é primordial para a vida nas cidades, pois abriga pessoas diferentes, em horários distintos, com interesses diversos. E Bui \& White (2017) afirmam que o acesso solar e o sombreamento ajudam a formar as qualidades espaciais e o ritmo de uso dos espaços públicos. Eles influenciariam o fluxo de pedestres nas ruas e, assim, também podem incidir quais praças terão atividades e comércio e quais ficarão improdutivas e até desertas.

Praças, por sua vez, são um especial tipo de espaço público, pelo destaque formal que apresenta no tecido urbano, pelas possibilidades que ela traz para a convivência social e interação política e pela sua importância ambiental — com áreas permeáveis, vegetadas e alagáveis (Topalov et al., 2014). Contudo, os municípios têm demonstrado dificuldades em lidar com as áreas de praças existentes, em razão das limitações orçamentárias e da gestão das demandas por terras para distintos usos urbanos. E as dinâmicas do cotidiano também impingem outras ordens de dificuldades, dado que os espaços privados de lazer têm, cada vez mais, tomado o lugar referencial das pessoas, uma vez que esses espaços públicos não conseguem traduzir as dinâmicas contemporâneas da própria sociedade que as abrigam. Por isso, quaisquer decisões normativas e legais que afetem a sua conformação física devem ser prontamente consideradas.

Tendo-se em vista o aumento na altura das edificações definido na última atualização das leis de zoneamento e uso do solo no município de Curitiba, Paraná, ocorrida em 2019, o presente texto tem por objetivo analisar o impacto do sombreamento proveniente de edificações do entorno através de simulações em três espaços públicos situados em diferentes zonas não totalmente consolidadas ou em expansão, que permitem edificações com pelos menos seis pavimentos.

\section{Opções metodológicas}

De início, indica-se algumas características do contexto espacial em análise. Assim, Curitiba, segundo a classificação de Köppen, localiza-se em região climática do tipo $\mathrm{Cfb}$, com clima subtropical úmido, mesotérmico, sem estação seca, com verões frescos e invernos com geadas frequentes e ocasionais e cada vez mais raras precipitações de neve (Álvares et. al, 2013). De acordo com Curitiba (2007), vários são os fatores que interferem na característica climática de Curitiba. Dentre os principais fatores estão a sua localização em relação ao Trópico de Capricórnio, a topografia do primeiro planalto, sua altitude média, como também a barreira geográfica natural da Serra do Mar. Conforme o Zoneamento Bioclimático Brasileiro estabelecido pela NBR — Norma Técnica Brasileira 15220-3 (ABNT, 2005), Curitiba se encontra na mais fria das oito zonas climáticas brasileiras, a Zona Bioclimática 1 , que corresponde a apenas $0,8 \%$ do território nacional. Sendo a mais fria entre as capitais brasileiras, apresenta desconforto térmico por frio durante a maior parte do ano, porém com mais intensidade no inverno (Schmitz \& Mendonça, 2011), justificando a necessidade de amplo acesso solar nos espaços públicos, principalmente nas épocas de frio intenso.

Curitiba teve seu primeiro Plano Diretor, para organização formal do espaço urbano, desenvolvido em 1943 pelo urbanista francês Alfred-Donat Agache, responsável também pelos planos implantados nas cidades do Rio de Janeiro e de Porto Alegre (Santos, 2015). Em 1966 foi implantado o plano WilheimIPPUC, no qual foi instituído um sistema de circulação viária através de vias estruturais que ligam o centro a porções periféricas do município. Assim, delineou-se uma forma de desenho espacial que é muito seguida até os dias de hoje e que determina a forma urbana de grandes porções urbanas do município.

Devido ao crescimento populacional a partir dos anos de 1970 e 80 ocorreu a verticalização dos primeiros Setores Estruturais e a formação de outros, como a área residencial Ecoville, no bairro Mossunguê, uma continuação do Setor Estrutural Oeste, onde foi criada a Zona Nova Curitiba em 1994, 
através do Decreto Municipal n 901/94, posteriormente revogado pelo Decreto Municipal no 191/00. Já no início dos anos 2000, segundo Schmitz \& Mendonça (2011) a Lei Municipal no 9800/00 (Curitiba, 2000), alterou a configuração linear da cidade para pluriaxial e, visando o horizonte futuro de crescimento populacional, foram definidos novos eixos de adensamento. Foram incluídos novos parâmetros de uso e ocupação do Solo para os terrenos ao longo do trecho urbano da antiga rodovia BR-116, que está sendo integrado à malha urbana e transformado no sexto eixo de transporte curitibano: a Linha Verde, cujos parâmetros urbanísticos visam o adensamento populacional e a verticalização. A partir de meados de 2015 ocorreu a última revisão do Plano Diretor Municipal, que originou a nova Lei de Zoneamento e Uso de Solo, Lei no 15511/19 (Curitiba, 2019), cujas mudanças principais tangem reequilibrar o uso misto, alterar coeficientes básicos e áreas de subsolo das áreas de grande adensamento, dentre outros.

De acordo com Martins (2019), em 2019 foi apresentada à Câmara Municipal de Curitiba um projeto de lei que autoriza conceder potencial construtivo adicional que tinha como objetivo estimular ainda mais o uso habitacional e comercial em algumas zonas especificas da metrópole, aumentado a densidade urbana, com finalidade de assegurar recursos financeiros para atender demandas da população. A aquisição de potencial construtivo adicional foi instituído no Decreto Municipal no 933/14 e, posteriormente, na Lei Municipal no 15661/20 (Curitiba, 2020), esta que permite o acréscimo do número de pavimentos constante em algumas zonas do munícipio. Devido à possibilidade de compra de potencial construtivo, algumas zonas poderiam ter o número de pavimentos aumentado em até $150 \%$, como no Eixo Conector Leste (denominado anteriormente Setor Especial Wenceslau Braz), e na Zona Residencial 3 de Transição (denominada anteriormente Zona Residencial Mercês), que integram dois dos espaços analisados neste estudo.

Com relação à metodologia adotada para a realização das simulações de sombreamento, foi empregado o método desenvolvido por Moro et al. (2019), que utilizam o software livre de Sistemas de Informações Geográficas (SIG) QGIS, o Package Shadow (Dorman et al., 2017) do software da linguagem estatística R versão 3.3.3, e um plugin em Phyton desenvolvido durante o estudo por Costa (2018), todos de código aberto, para estimar, compreender, analisar e visualizar o sombreamento em espaços públicos.

0 método segue diferentes etapas, a partir de dados cadastrais abertos disponibilizados virtualmente e são desenhadas no QGIS os polígonos das edificações de entorno do espaço a ser estudado. Para as simulações de cenário possível foram avaliados os afastamentos das divisas, obedecendo o estipulado na Lei Municipal no 15.511/19 (Curitiba, 2019). Para cada polígono foi atribuído a altura obtida através da ferramenta de medição do Google Earth Pro, recurso este validado por Pinto (2019). Na sequência, tendo como base o arquivo formato shapefile dos polígonos das edificações de entorno gerado, foi executada a simulação da trajetória das sombras das edificações de entorno imediato, com a utilização do plug-in "Package Shadow", desenvolvido por Dorman et al. (2017), no software de estatística R. Posteriormente, no software QGIS, os arquivos das sombras gerados no software de linguagem estatística $\mathrm{R}$ foram transformados em arquivos formato raster. A partir da Álgebra de Mapas foram gerados os Mapas de Acúmulos de Sombra, que representam visualmente a quantidade de sombra acumulada no período analisado a partir de um dégradé de cores, e os Mapas de Zoneamento das Sombras, que dividem o espaço em zonas de acordo com o período de horas atingido pelo sombreamento, sendo estes divididos entre até 03 horas, de 03 a 05 horas e com mais de 05 horas (Figura 1). Parte do processo descrito foi automatizado por Costa (2018), com o intuito de facilitar e agilizar o processo de geração de sombras (Moro et al., 2019). 


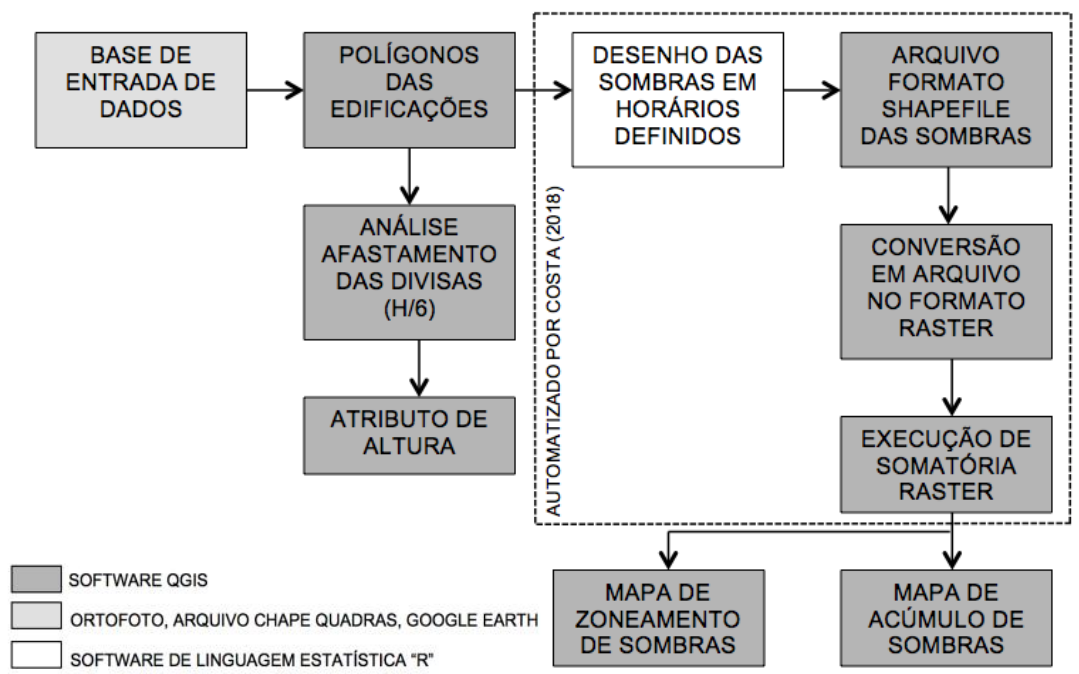

Figura 1 - Fluxograma das etapas do método de simulação. Fonte: adaptado de Moro et al. (2019).

As datas escolhidas para análise foram as do solstício de verão, solstício de inverno e equinócios, com intervalo de horário definido das $8 \mathrm{~h}$ às $16 \mathrm{~h}$, e simulações realizadas a cada 15 minutos. Como resultado foram gerados Mapas de Acúmulo de Sombras os Mapas de Zoneamento de Sombras².

De acordo com Ribeiro (2019), com base em dados da Secretaria Municipal do Meio Ambiente e do IPPUC, até 2019, existiriam 1.026 praças em Curitiba. Diante desse panorama, a escolha dos espaços a serem analisados foi feita a partir de arquivos de dados geográficos em formato shapefile, disponibilizados pela gestão municipal (IPPUC, 2019), observando os seguintes critérios: (1) espaços situados em zonas não consolidadas totalmente, no qual se permite a altura mínima de seis pavimentos, e onde, até o momento, mesmo com grandes alturas permitidas, existam edificações de altura baixa ou mesclada (baixa e alta), ou lotes vagos. Além disso, também foi verificada a existência de espaços em zonas em expansão nas quais, com as atualizações no Plano Diretor Municipal, poderiam existir lotes com possiblidade de serem construídas edificações de grande porte e altura, promovendo assim a verticalização do local (Tabela 1).

Tabela 1 - Pré-seleção das zonas com edificações de altura mínima de seis pavimentos e número de espaços existentes em cada um deles.

\begin{tabular}{llllll}
\hline & Zoneamento & $\begin{array}{l}\mathbf{N}^{\circ} \text { de } \\
\text { pavimentos Lei } \\
\text { Zoneamento } \\
\mathbf{9 8 0 0 / 2 0 0 0}\end{array}$ & $\begin{array}{l}\mathbf{N}^{\circ} \text { de pavimentos } \\
\text { Lei Aquisição } \\
\text { Pot.Construtivo }\end{array}$ & $\begin{array}{l}\mathbf{N}^{\circ} \text { de pavimentos } \\
\text { nova Lei de } \\
\text { Zoneamento } \\
\mathbf{1 5 6 6 1 / 2 0}\end{array}$ & $\begin{array}{l}\text { Número } \\
\text { de } \\
\text { espaços } \\
\text { existentes }\end{array}$ \\
\hline 1 & Polo da Linha Verde & Livre & - & Livre & 8 \\
2 & Setor Especial Conector & 4 & - & 8 & 19 \\
3 & Setor Especial da Linha Verde & 6 & - & 10 & 5 \\
4 & Setor Especial do Centro Cívico & Livre/6 & 10 & 6 & 15 \\
5 & Setor Especial Estrutural & Livre & - & - & 43 \\
6 & Setor Especial Marechal Floriano & 4 & 10 & 10 & 6 \\
7 & Setor Especial Nova Curitiba (Via Ext.) & Livre & - & 10 & 6 \\
8 & Setor Especial Pres. Wenceslau Braz & 4 & 10 & Livre & 10 \\
9 & Zona Central & Livre & Cone & 8 & 13 \\
10 & Zona de Transição Nova Curitiba & 6 & 8 & 8 & 15 \\
11 & Zona Residencial 4 & 6 & 8 & 10 & 131 \\
12 & Zona Residencial 4 Linha Verde & 6 & - & - & 1 \\
13 & Zona Residencial Mercês & 2 & 8 & & 1 \\
\hline
\end{tabular}

Fonte: Adaptado de Pinto (2019).

\footnotetext{
2 Nessa pesquisa não foram considerados parâmetros de conforto devido à necessidade de utilizar outros softwares para executar tais análises. Todavia, entendemos que poderiam ser perfeitamente incluídos em análises futuras.
} 
Como o método de análise de sombreamento é baseado em imagens de satélite, outros critérios também foram adotados para a escolha dos espaços, entre eles a quantidade de arborização no local. Sendo assim, foram selecionados três espaços: a Praça da Ucrânia, o Centro Esportivo Arnaldo Faivro Busato 04 e a Praça Cova da Iria.

A praça da Ucrânia, criada na década de 1960 e com área de $2.741 \mathrm{~m}^{2}$, está localizada no Bairro Bigorrilho, no limítrofe da Zona Estrutural e da Zona Residencial 3 de Transição (anteriormente denominada Residencial Mercês), na região noroeste do município, tendo como entorno edificações altas e residências baixas. 0 maior movimento no local acontece às sextas-feiras, quando acolhe, desde 1993, a feira noturna de alimentação, intitulada Sabores do Mundo, e aos fins de semana.

o Centro Esportivo Arnaldo Faivro Busato 04 foi criado na década de 1980, está localizado no Bairro Lindoia, na Avenida Presidente Wenceslau Braz, inserido no Eixo Conector Leste (denominado anteriormente Zona Setor Especial Presidente Wenceslau Braz), na região centro-leste do município. Possui uma área de $10.255 \mathrm{~m}^{2}$, e entorno mesclado de edificações residenciais e comerciais, em sua maioria com baixa altura atualmente, mas o gabarito máximo permitido para novas edificações salta de quatro para dez pavimentos, quando aplicado o Decreto Municipal no 933/2014 ou a nova Lei de Zoneamento de Curitiba. É frequentado principalmente por jovens devido às quadras esportivas existentes.

Já a Praça Cova da Íria, com uma área de $5.106 \mathrm{~m}^{2}$, está localizada no Polo da Linha Verde, na região nordeste da cidade, área de interesse municipal por ser um importante eixo de desenvolvimento da cidade. Atualmente o entorno imediato é composto por construções de baixa altura, em sua maioria do tipo comercial. De acordo com a Lei Municipal no 13.909/2011 (Curitiba, 2011), o setor compreende áreas de ocupação diferenciada de média e alta densidade onde se pretende desenvolver o adensamento, a verticalização e a predominância de usos comerciais e de serviços, com edificações de altura livre (Figuras 2 e 3$)^{3}$.

\section{Sombras nas praças curitibanas}

Para o espaço Praça da Ucrânia foram executadas duas simulações. A primeira, com o cenário atual de edificações de entorno composta de edificações de variadas alturas e, a segunda, com um possível cenário considerando a altura limítrofe de edificações de entorno, situadas a nordeste da praça, e também seus afastamentos das divisas de acordo com o recomendado na Lei Municipal no 15.511/19 (Curitiba, 2019).

Para o espaço Centro Esportivo Arnaldo Faivro Busato 04 foram executadas também duas simulações. A primeira com o cenário atual de edificações de entorno, composta por edificações de distintas alturas. A segunda sessão foi executada considerando uma nova configuração de lotes e de edificações de entorno imediato do espaço analisado, levando-se em consideração também os afastamentos das divisas de acordo com o recomendado na mesma lei.

Já no terceiro espaço escolhido, Praça Cova da Iria, foram executadas três simulações. A primeira com o cenário atual e as outras duas com configurações possíveis de edificações, aplicando-se o índice básico da legislação e outra considerando-se a aquisição de potencial construtivo, ambos levando-se em consideração também os afastamentos das divisas de acordo com o recomendado na lei municipal.

\footnotetext{
${ }^{3}$ A presença de árvores não foi considerada no estudo devido a sua vida útil, por proporcionar um tipo de sombreamento diferente, e por poder ser retirada a qualquer momento.
} 

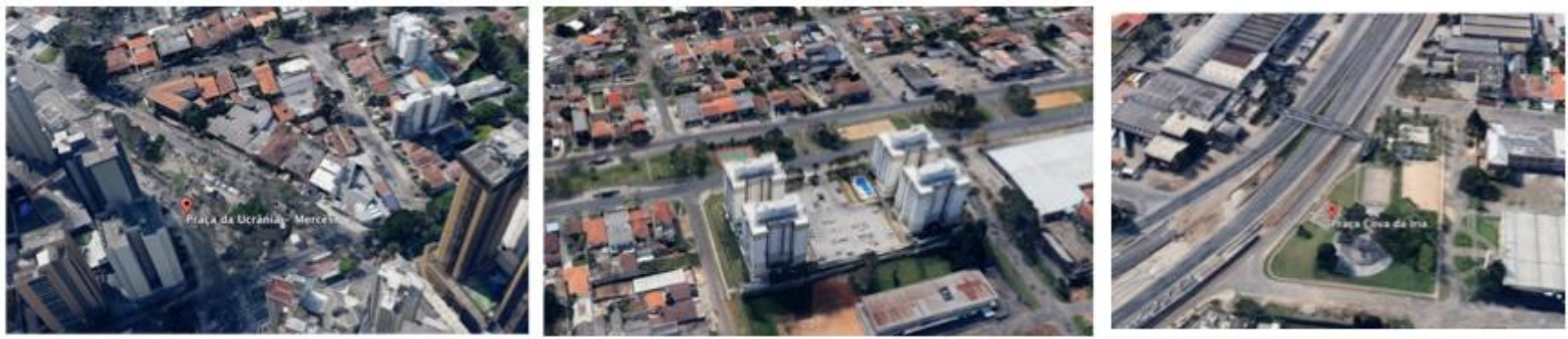

Figura 2 - Imagem aérea da Praça da Ucrânia, Centro Esportivo Arnaldo Busato 4, e Praça Cova da Iria. Fonte: Google Earth Pro 3D® (2020).

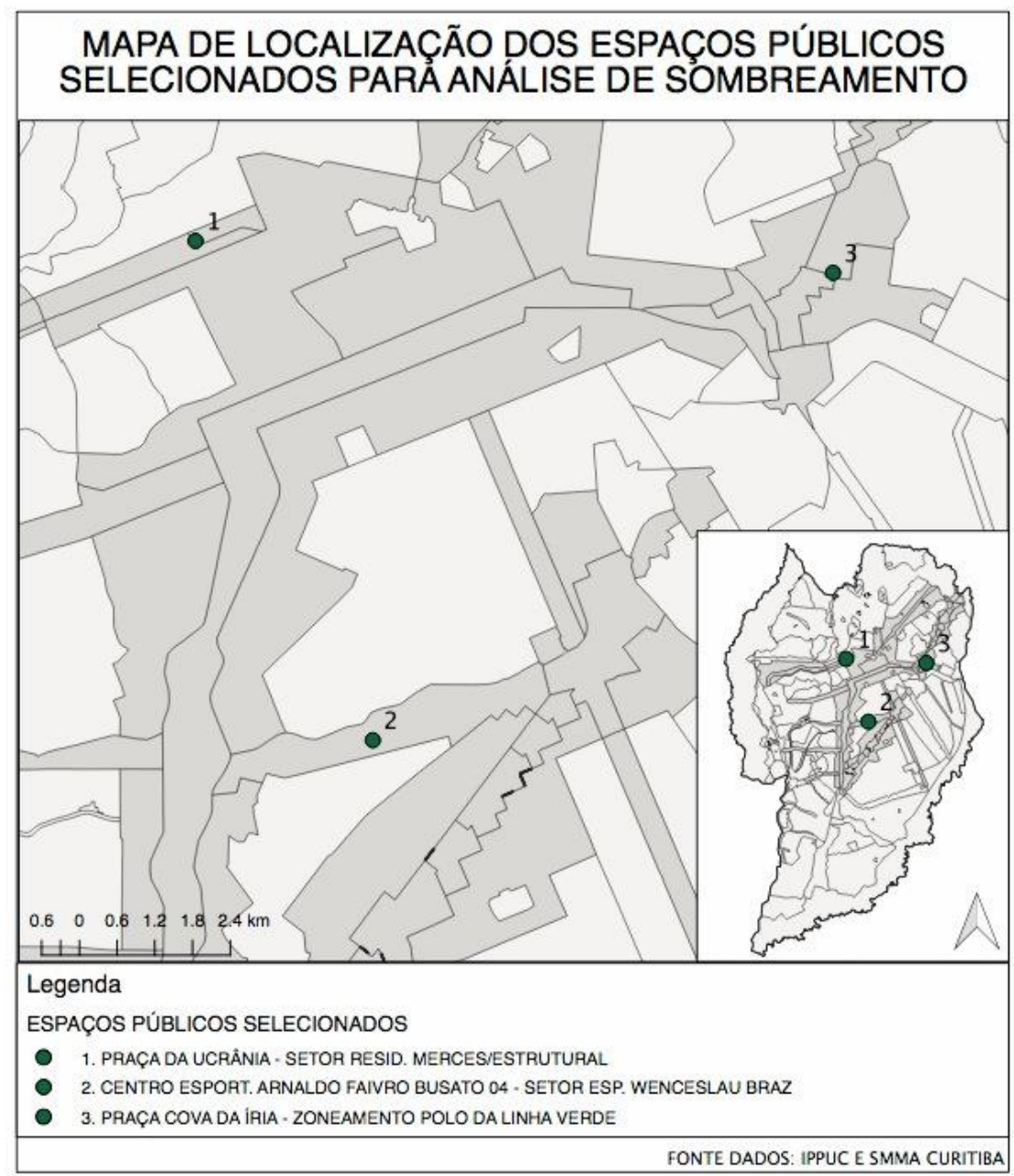

Figura 3 - Mapa de localização dos espaços selecionados para análise. Fonte: Pinto (2019).

\section{Análises da Praça da Ucrânia}

A primeira sessão de simulações na Praça da Ucrânia foi considerada a configuração atual de altura das edificações, composta atualmente de edificações de grande altura à oeste da praça, e de edificações com baixa altura à nordeste da praça. Já a segunda sessão de simulação, de cenário possível, considerou todos os lotes situados à nordeste da praça com a altura de oito pavimentos, ou aproximadamente $30 \mathrm{~m}$, máximo permitido pelo novo zoneamento, com aquisição de potencial construtivo (Figura 4 e Tabela 2). 


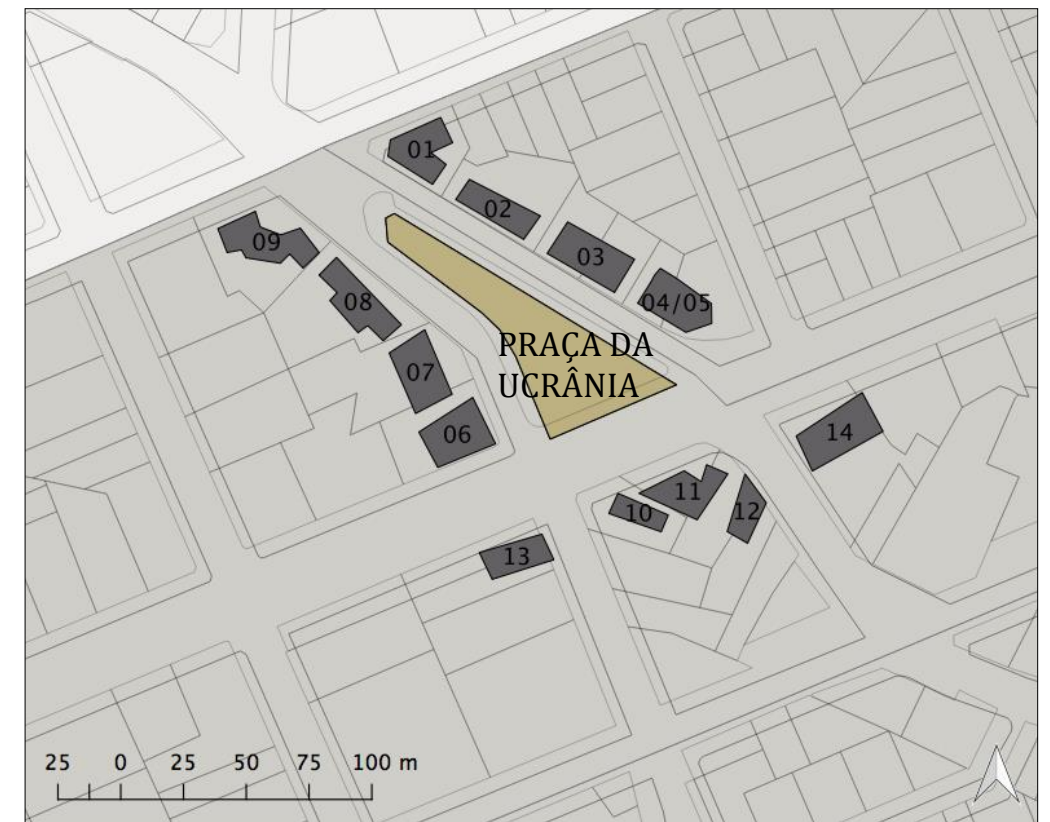

Figura 4 - Praça da Ucrânia - Configuração de edificações de entorno nas simulações. Fonte: Pinto (2019).

Tabela 2 - Alturas das edificações de entorno da Praça da Ucrânia consideradas nas simulações.

\begin{tabular}{lccc}
\hline Item & $\begin{array}{l}\text { Altura das edificações de } \\
\text { entorno existentes }(\mathbf{m})\end{array}$ & $\begin{array}{l}\text { Altura das edificações de entorno com } \\
\text { aquisição de Potencial Construtivo(m) }\end{array}$ & $\begin{array}{l}\text { Afastamento Divisas - } \mathbf{h} / 6- \\
\text { edificações à nordeste da praça } \\
(\mathbf{m})\end{array}$ \\
\hline 01 & 8,05 & 30,00 & 5,00 \\
02 & 25,00 & 30,00 & 5,00 \\
03 & 5,50 & 30,00 & 5,00 \\
04 & 4,00 & 30,00 & 5,00 \\
05 & 3,45 & 30,00 & 5,00 \\
06 & 50,18 & 50,18 & - \\
07 & 73,40 & 73,40 & - \\
08 & 61,06 & 61,06 & - \\
09 & 62,80 & 62,80 & - \\
10 & 53,07 & 53,07 & - \\
11 & 10,30 & 10,30 & - \\
12 & 47,90 & 47,90 & - \\
13 & 5,7 & 5,7 & - \\
14 & 106,90 & 106,90 & - \\
\hline
\end{tabular}

Fonte: os autores.

O resultado das simulações representados através dos Mapas de Acúmulo de Sombras e dos Mapas de Zoneamento de Sombras demonstraram que o impacto do sombreamento das edificações sobre a praça é significativamente maior, se o cenário de aumento das alturas das edificações for concretizado. Sendo que o maior impacto observado nos mapas aparece na data de solstício de inverno, onde uma grande área do espaço público analisado é sombreado por mais de três horas (Figuras 5 e 6). 


\section{CENÁRIO ATUAL}

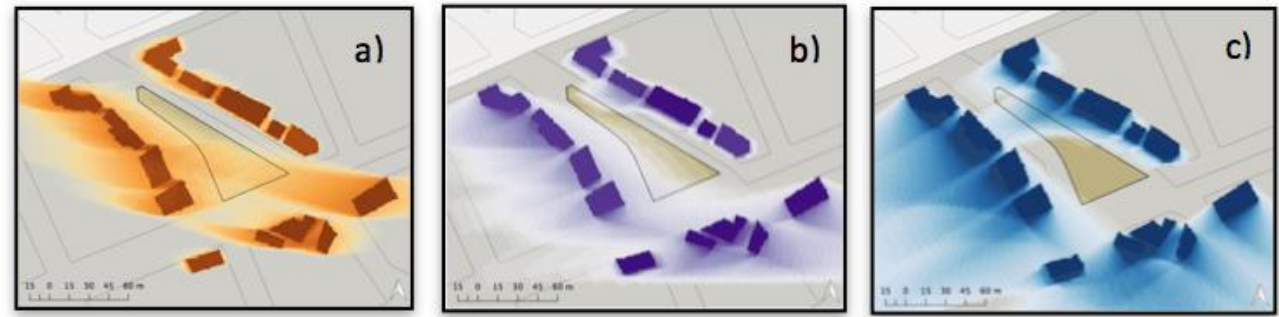

CENÁRIO POSSÍVEL COM AQUISIÇÃO DE POTENCIAL CONSTRUTIVO
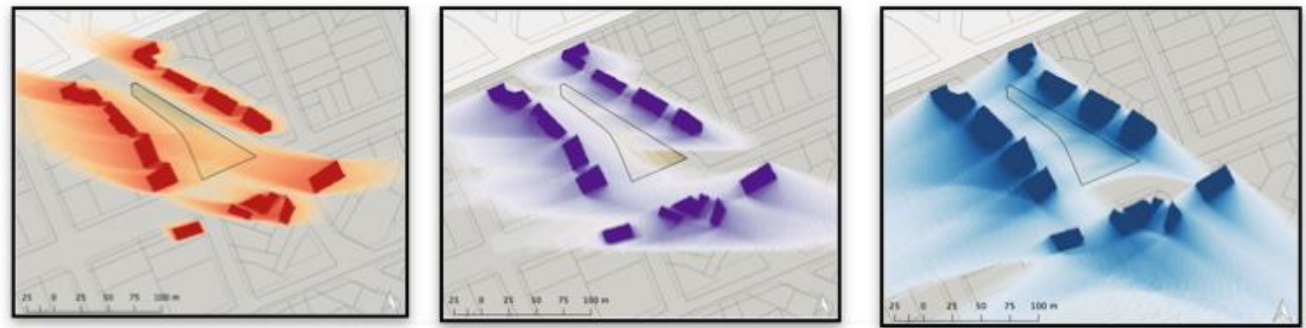

Legenda
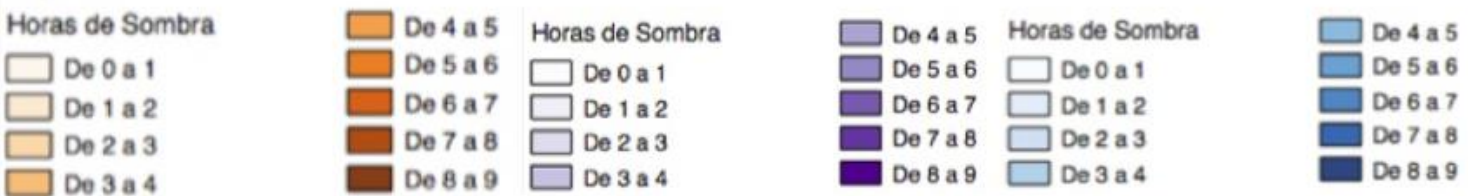

Figura 5 - Comparação dos Mapas de Acúmulo de Sombras na Praça Ucrânia - cenários atual e simulado - Solstício de verão (a) e Equinócio de Primavera (b), Solstício de inverno (c). Fonte: Pinto (2019).

CENÁRIO ATUAL
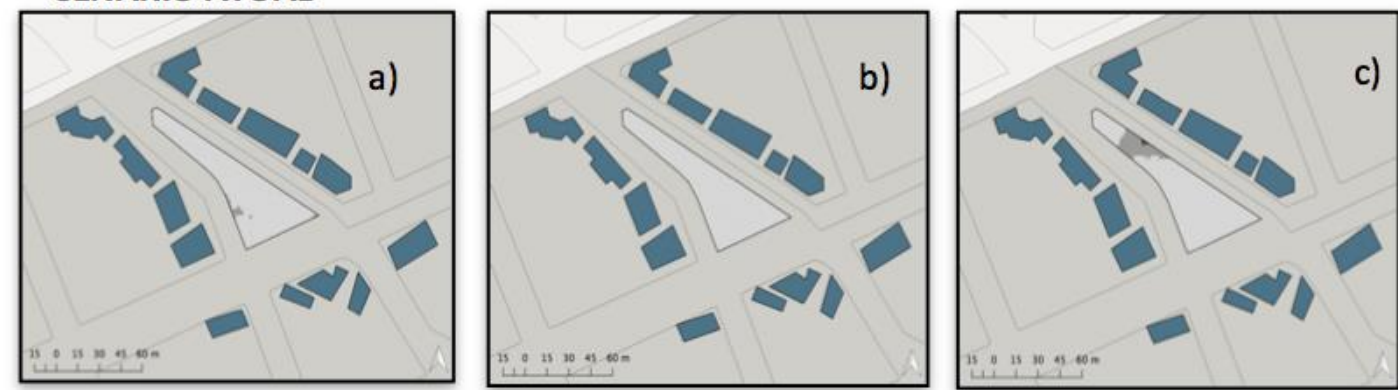

CENÁRIO POSSÍVEL COM AQUISIÇÃO DE POTENCIAL CONSTRUTIVO
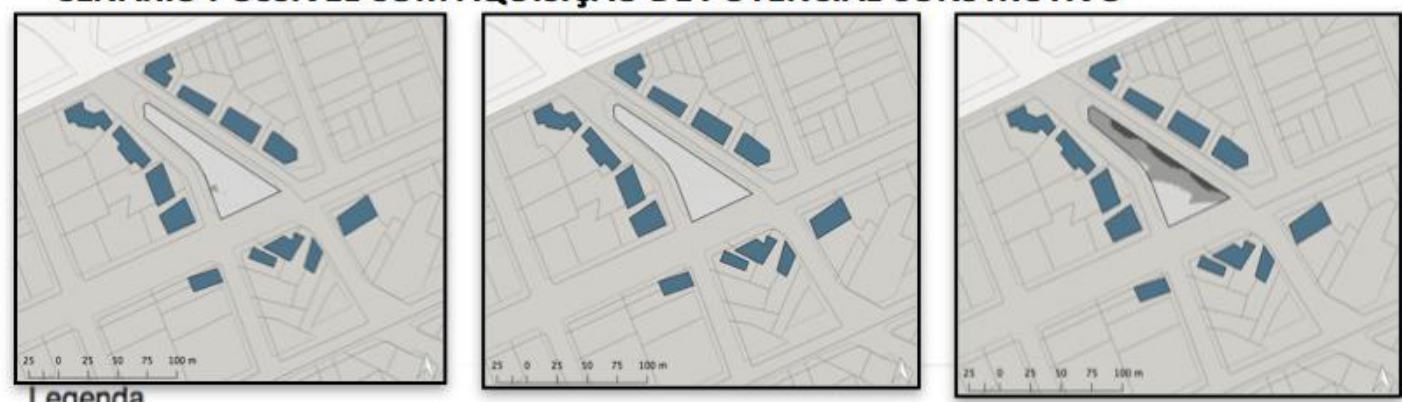

$$
\begin{aligned}
& \text { Zoneamento de Sombras (Horas) } \\
& \text { Até } 3 \text { horas de sombra } \\
& \text { Entre } 3 \text { e } 5 \text { horas de sombra } \\
& \text { Mais de } 5 \text { horas de sombra }
\end{aligned}
$$

Figura 6 - Comparação dos Mapas de Zoneamento de Sombras na Praça Ucrânia - cenários atual e simulado - Solstício de verão (a) e Equinócio de Primavera (b), Solstício de inverno (c). Fonte: Pinto (2019). 


\section{Análises do Centro Esportivo Arnaldo Busato 04}

Na primeira sessão de simulação no centro Esportivo Arnaldo Busato 4 foi considerada a altura existente de edificações; já na simulação de cenário possível foi executada uma nova configuração de lotes e de edificações de entorno considerando-se a aquisição de potencial construtivo, ou seja, 10 pavimentos, e levando-se em consideração também os afastamentos das divisas de acordo com o recomendado na Lei Municipal n¹5.511/19 (Curitiba, 2019). A configuração de edificações no cenário possível foi baseada, em quase sua totalidade, na planta e dimensão de quatro edificações do tipo torre existentes atualmente no entorno (Figura 2). Nesta nova configuração o número de edificações de entorno seria menor devido ao afastamento das divisas e configuração dos lotes (Figura 7 e Tabela 3).
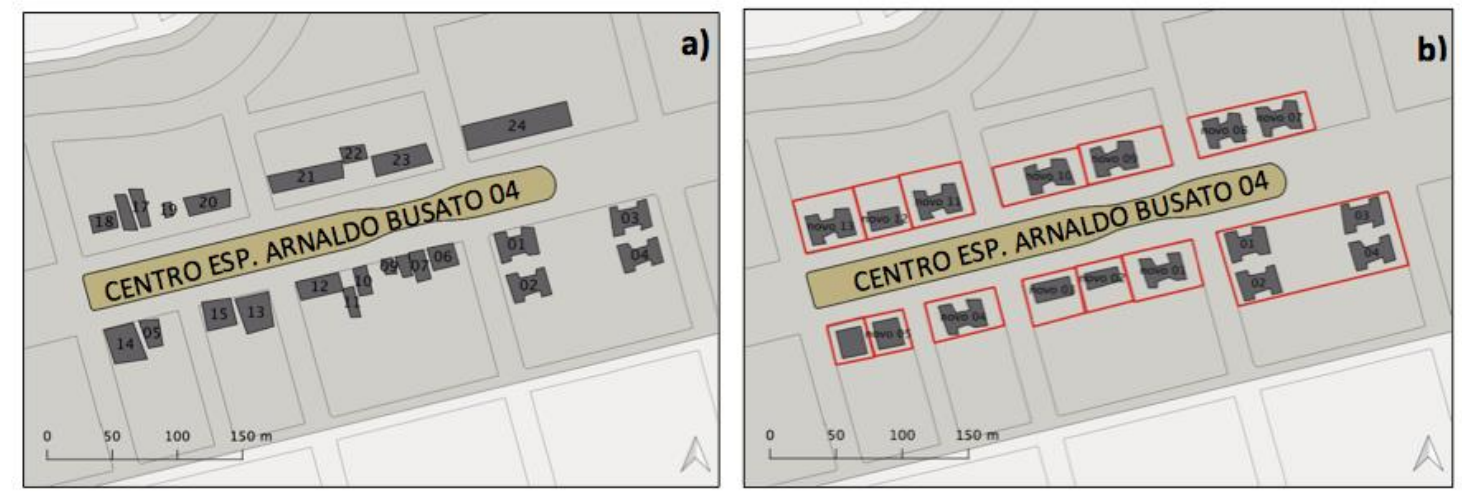

Figura 7- Centro Esportivo Arnaldo Busato 04 - Configuração de edificações de entorno existentes (a), configuração de lotes e edificações em cenário possível (b) aplicadas nas simulações. Fonte: Adaptado de Pinto (2019).

Tabela 3 - Alturas das edificações de entorno do Centro Esportivo Arnaldo Busato 04 consideradas nas simulações.

\begin{tabular}{|c|c|c|c|}
\hline Item & $\begin{array}{l}\text { Altura das edificações de } \\
\text { entorno existentes }(\mathrm{m})\end{array}$ & $\begin{array}{l}\text { Altura das edificações de entorno no } \\
\text { cenário possível com aquisição de } \\
\text { Potencial Construtivo(m) }\end{array}$ & $\begin{array}{l}\text { Afastamento Divisas no cenário } \\
\text { possível - } h / 6(\mathrm{~m})\end{array}$ \\
\hline 01 & 30,80 & 30,80 & - \\
\hline 02 & 30,80 & 30,80 & - \\
\hline 03 & 30,80 & 30,80 & - \\
\hline 04 & 30,80 & 30,80 & - \\
\hline 05 & 5,26 & 30,00 & 5,00 \\
\hline 06 & 12,40 & 30,00 & 5,00 \\
\hline 07 & 3,00 & 30,00 & 5,00 \\
\hline 08 & 5,80 & 30,00 & 5,00 \\
\hline 09 & 3,25 & 30,00 & 5,00 \\
\hline 10 & 4,90 & 30,00 & 5,00 \\
\hline 11 & 4,90 & 30,00 & 5,00 \\
\hline 12 & 2,90 & 30,00 & 5,00 \\
\hline 13 & 4,50 & 30,00 & 5,00 \\
\hline 14 & 5,00 & 30,00 & 5,00 \\
\hline 15 & 3,00 & 30,00 & 5,00 \\
\hline 16 & 3,00 & 30,00 & 5,00 \\
\hline 17 & 3,00 & 30,00 & 5,00 \\
\hline 18 & 3,50 & - & - \\
\hline 19 & 3,00 & - & - \\
\hline 20 & 3,00 & - & - \\
\hline 21 & 2,80 & - & - \\
\hline 22 & 5,00 & - & - \\
\hline 23 & 3,40 & - & - \\
\hline 24 & 3,50 & - & - \\
\hline
\end{tabular}

Fonte: Autores. 
Comparando-se os diferentes Mapas de Acúmulos de Sombra e os Mapas de Zoneamentos de Sombras nas diferentes datas analisadas, pôde-se observar que o impacto do sombreamento sobre a praça é significativamente maior, principalmente no solstício de inverno, onde grande parte do espaço é sombreada por mais de três horas (Figuras 8 e 9).

\section{CENÁRIO ATUAL}
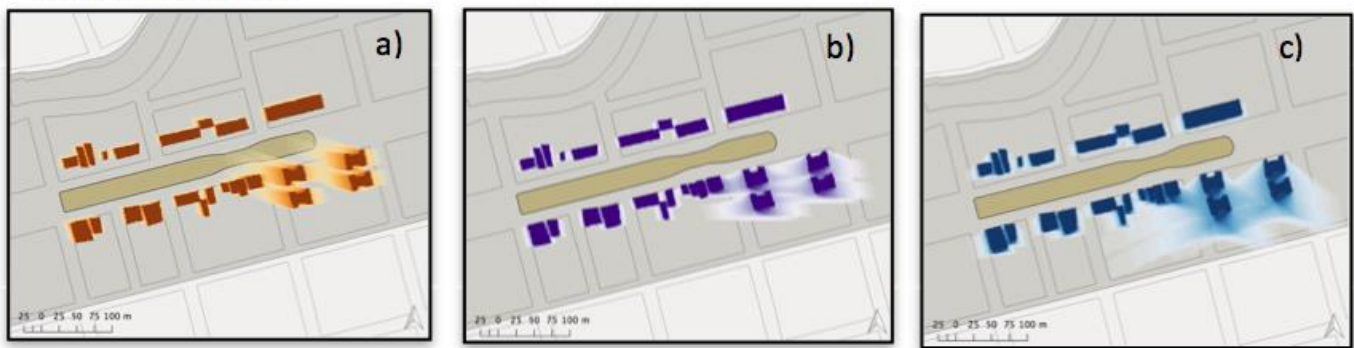

\section{CENÁRIO POSSÍVEL COM AQUISIÇÃO DE POTENCIAL CONSTRUTIVO}
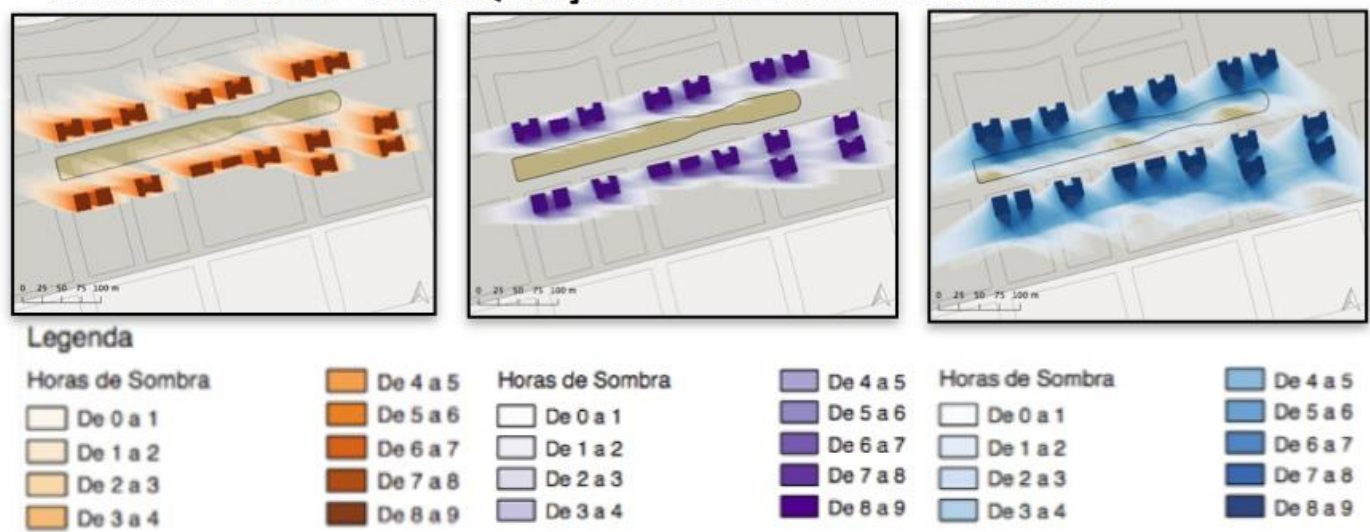

Figura 8 - Comparação dos Mapas de Acúmulo de Sombras no Centro Esportivo Arnaldo Busato 04 - cenários atual e simulado - Solstício de verão (a) e Equinócio de Primavera (b), Solstício de inverno (c). Fonte: Adaptado de Pinto (2019).

\section{CENÁRIO ATUAL}
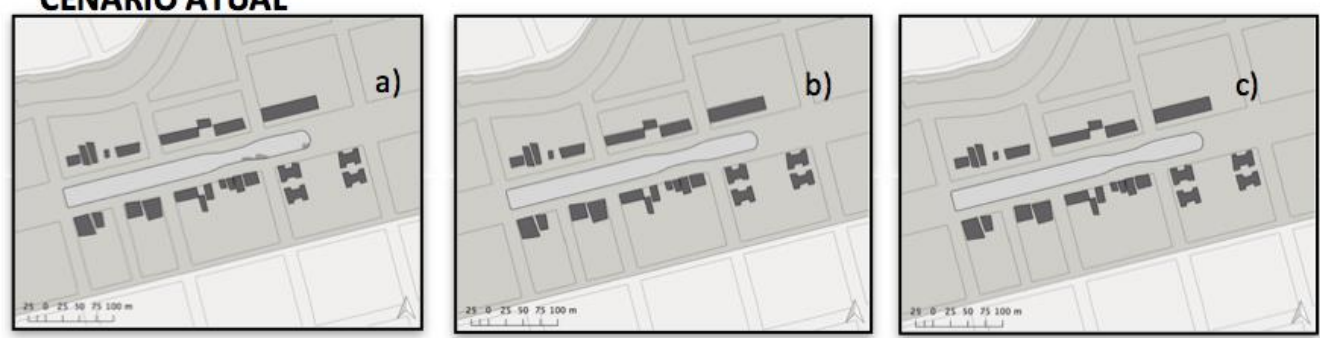

CENÁRIO POSSÍVEL COM AQUISIÇÃO DE POTENCIAL CONSTRUTIVO

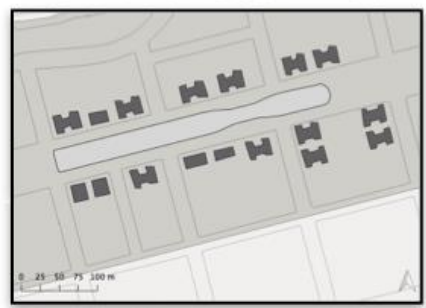

\section{Legenda}

Zoneamento de Sombras (Horas)

Até 3 horas de sombra

Entre 3 e 5 horas de sombra

Mais de 5 horas de sombra (1) 


\section{Análises da Praça Cova da Iria}

Na primeira sessão de simulação na Praça Cova da Iria foi considerada a altura existente de edificações com aproximadamente oito metros de altura; já nas simulações de cenário possível foram aplicados os parâmetros estipulados e permitidos na nova lei de zoneamento. Considerou-se que a construção de edifícios nos lotes menores só seria viável comercialmente se fossem agrupados em lotes de maior área, sendo assim foi simulada uma nova configuração, unindo-se alguns dos lotes no entorno imediato (Figura 10). As edificações de entorno ao sul não foram consideradas por estarem em zonas diferentes, que não permitem grande verticalização.
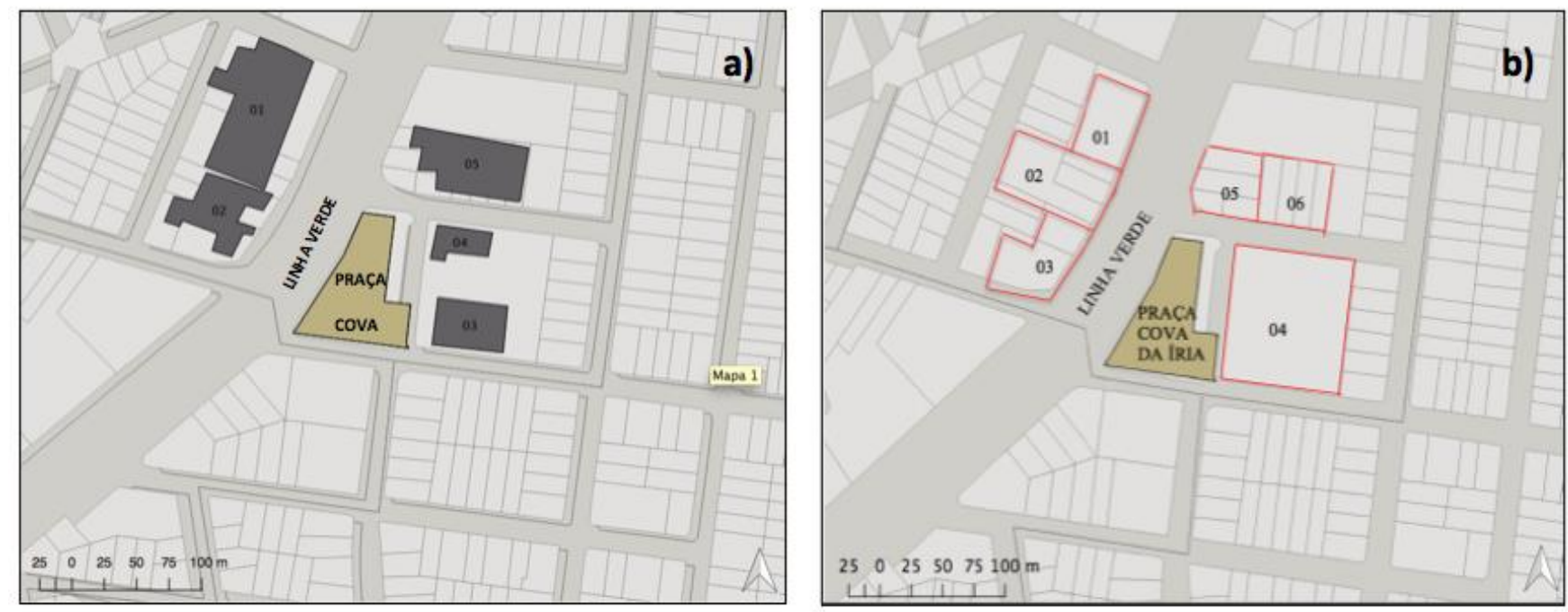

Figura 10 - Configuração de edificações de entorno existentes atualmente (a) e de possível configuração futura de lotes de entorno (b). Fonte: autores (a) e Pinto (2019) (b).

Por se tratar de uma região em expansão, a partir desta configuração dos lotes, foi executado um estudo de implantação de edificações em torre com planta de $500 \mathrm{~m}^{2}$ a fim de verificar o possível impacto de sombreamento sobre o referido espaço público. A partir dos índices da legislação, no que se refere ao valor do coeficiente de aproveitamento e a taxa de ocupação, e considerando a metragem estipulada das edificações, a altura das edificações alcançaria entre seis e nove pavimentos; para a estimativa de afastamento das divisas foi considerado o pé direito de quatro metros entre pavimentos (Tabela 4).

Tabela 4 - Estudo de implantação de edificações no entorno para análise da Praça Cova da Íria situada no Polo da Linha Verde com índices básicos da legislação.

\begin{tabular}{llllllll}
\hline Item & $\begin{array}{l}\text { Área do } \\
\text { Lote } \\
\left(\mathbf{m}^{2}\right)\end{array}$ & $\begin{array}{l}\text { Coeficiente de } \\
\text { Aproveitamento }\end{array}$ & $\begin{array}{l}\text { Taxa de } \\
\text { Ocupação }\end{array}$ & $\begin{array}{l}\text { Planta } \\
\text { torre } \\
\left(\mathbf{m}^{2}\right)\end{array}$ & $\begin{array}{l}\text { Quantidade } \\
\text { de torres }\end{array}$ & $\begin{array}{l}\text { Quantidade } \\
\text { de } \\
\text { pavimentos }\end{array}$ & $\begin{array}{l}\text { Afastamento } \\
\text { Divisas - } \mathbf{h} / 6 \\
(\mathbf{m})\end{array}$ \\
\hline 01 & 3.355 & 1 & $50 \%$ & 500 & 1 & 7 & 4,65 \\
02 & 3.221 & 1 & $50 \%$ & 500 & 1 & 7 & 4,65 \\
03 & 3.404 & 1 & $50 \%$ & 500 & 1 & 7 & 4,65 \\
04 & 9.400 & 1 & $50 \%$ & 500 & 2 & 9 & 6,00 \\
05 & 2.750 & 1 & $50 \%$ & 500 & 1 & 6 & 4,00 \\
06 & 2750 & 1 & $50 \%$ & 500 & 1 & 6 & 4,00 \\
\hline
\end{tabular}

Fonte: adaptado de Pinto (2019).

Em outra configuração, caso houvesse aquisição de potencial construtivo adicional, a altura das edificações poderia sofrer um grande acréscimo. Nesse caso, o coeficiente de aproveitamento máximo poderia ser quatro vezes maior (Tabela 5). 
Tabela 5 - Estudo de implantação de edificações no entorno para análise da Praça Cova da Íria situada no Polo da Linha Verde aquisição de Potencial Construtivo.

\begin{tabular}{llllllll}
\hline Item & $\begin{array}{l}\text { Área do } \\
\text { Lote } \\
\left(\mathbf{m}^{\mathbf{2}}\right)\end{array}$ & $\begin{array}{l}\text { Coeficiente de } \\
\text { Aproveitamento }\end{array}$ & $\begin{array}{l}\text { Taxa de } \\
\text { Ocupação }\end{array}$ & $\begin{array}{l}\text { Planta } \\
\text { torre } \\
\left(\mathbf{m}^{2}\right)\end{array}$ & $\begin{array}{l}\text { Quantidade } \\
\text { de torres }\end{array}$ & $\begin{array}{l}\text { Quantidade de } \\
\text { pavimentos }\end{array}$ & $\begin{array}{l}\text { Afastamento } \\
\text { Divisas - h/6 } \\
(\mathbf{m})\end{array}$ \\
\hline 01 & 3.355 & 4 & $50 \%$ & 500 & 1 & 26 & 17,30 \\
02 & 3.221 & 4 & $50 \%$ & 500 & 1 & 26 & 17,30 \\
03 & 3.404 & 4 & $50 \%$ & 500 & 1 & 26 & 17,30 \\
04 & 9.400 & 4 & $50 \%$ & 500 & 3 & 25 & 16,65 \\
05 & 2.750 & 4 & $50 \%$ & 500 & 1 & 22 & 14,65 \\
06 & 2750 & 4 & $50 \%$ & 500 & 1 & 22 & 14,65 \\
\hline
\end{tabular}

Fonte: adaptado de Pinto (2019).

A partir desses estudos foram feitas as sessões de simulação, sendo a primeira sessão considerando o cenário atual de edificações de entorno, a segunda sessão considerando um cenário com edificações de altura baseada nos índices básicos da legislação, e a terceira sessão considerando as edificações com potencial adicional máximo de construção, com o coeficiente de aproveitamento igual a quatro. Para esta última, foram consideradas edificações no entorno imediato com altura média de 24 pavimentos ou aproximadamente 70 metros.

Como resultado pôde-se observar que na condição atual de edificações de entorno não há sombreamento incidente sobre a praça, já na segunda simulação quando se respeita o índice básico da legislação, o impacto de sombreamento sobre praticamente toda a área do espaço público analisado foi de até três horas, em todas as datas analisadas. Já o maior impacto de sombreamento sobre a praça analisada ocorre no solstício de inverno, em razão das alturas das edificações obtidas com a aquisição de potencial construtivo. Nos Mapas de Zoneamento de Sombras é possível ter uma melhor visualização do real impacto do sombreamento nos diferentes cenários. Quando aplicado o índice básico da legislação, o número máximo de horas de sombreamento limita-se a três. Já quando se considera a aquisição de potencial construtivo, o sombreamento atinge uma área bem maior do espaço e por um período de horas mais estendido (Figuras 11 e 12). 
CENÁRIO ATUAL
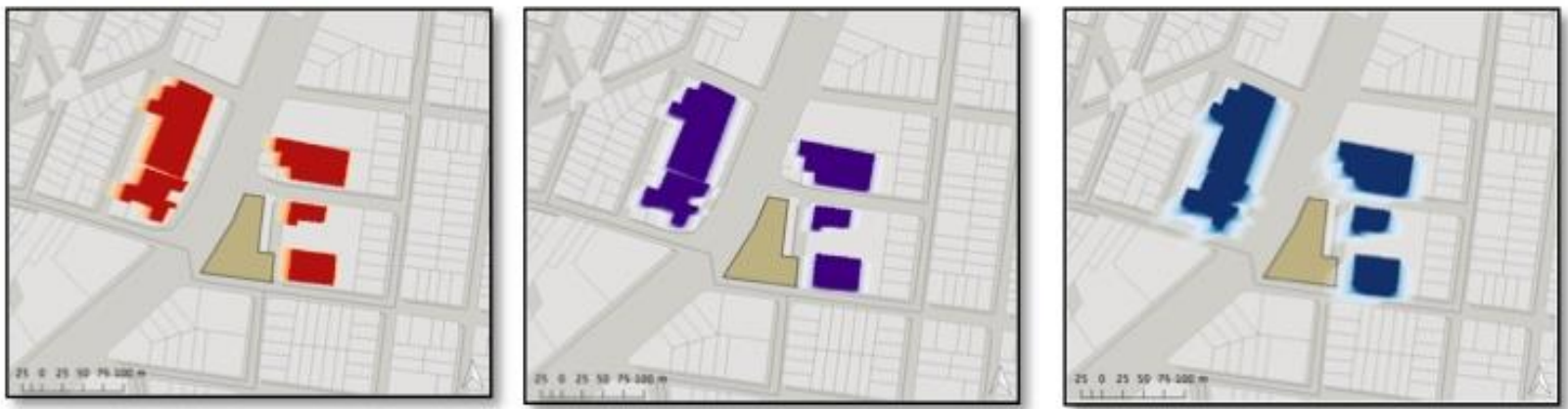

CENÁRIO POSSÍVEL COM ÍNDICE BÁSICO
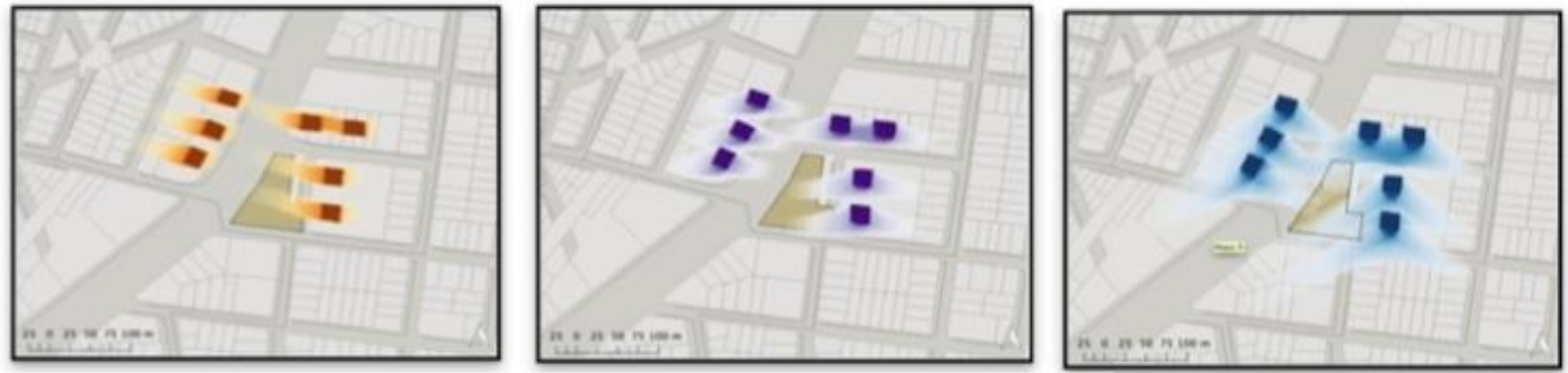

\section{CENÁRIO POSSÍVEL COM AQUISIÇÃO DE POTENCIAL CONSTRUTIVO}
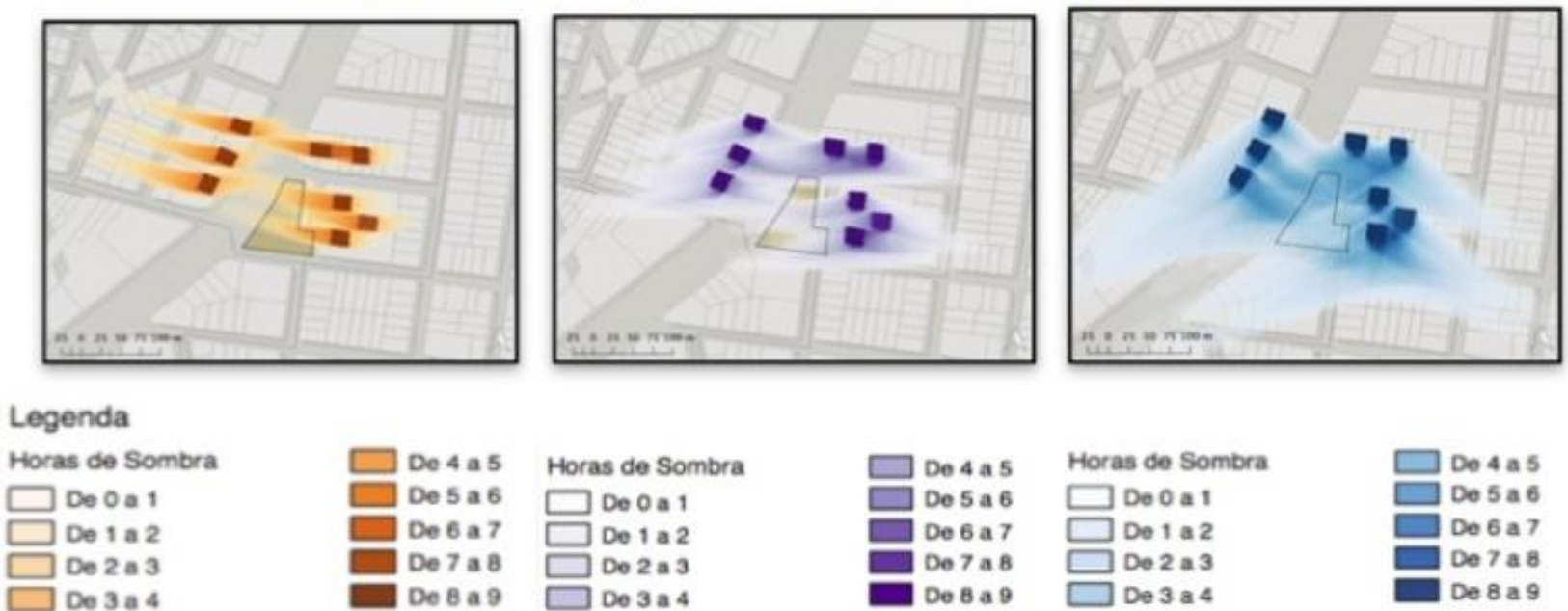

Figura 11 - Comparação dos Mapas de Acúmulo de Sombras na Praça Cova da Iria - cenários atual, possível com Índice Básico e com aquisição de potencial construtivo - Solstício de verão (a) e Equinócio de Primavera (b), Solstício de inverno (c). Fonte: Pinto (2019). 


\section{CENARIO ATUAL}
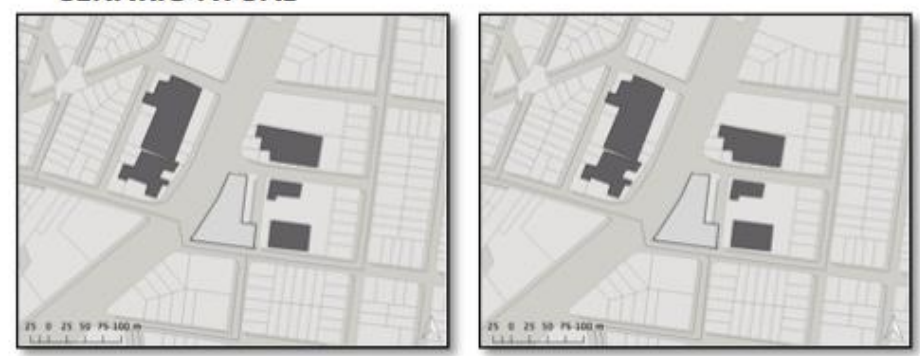

CENÁRIO POSSÍVEL COM ÍNDICE BÁSICO
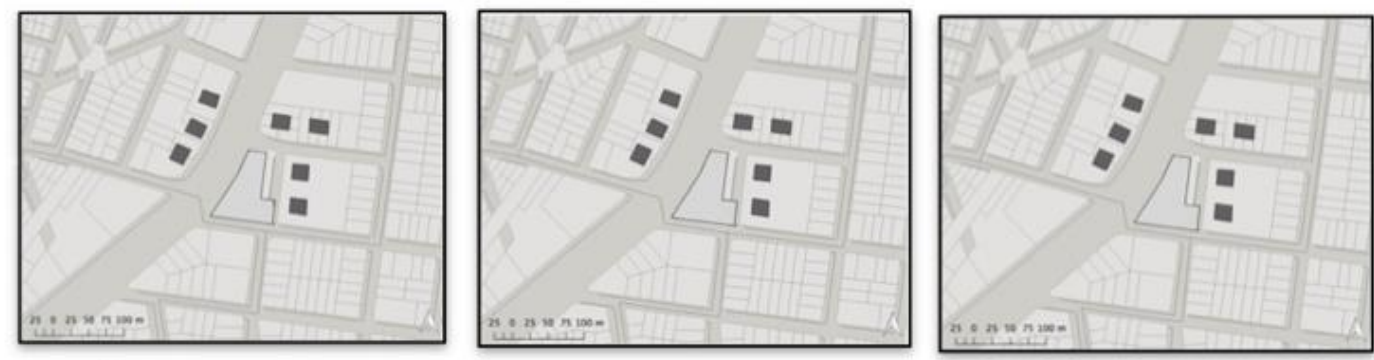

CENÁRIO POSSÍVEL COM AQUISIÇÃO DE POTENCIAL CONSTRUTIVO
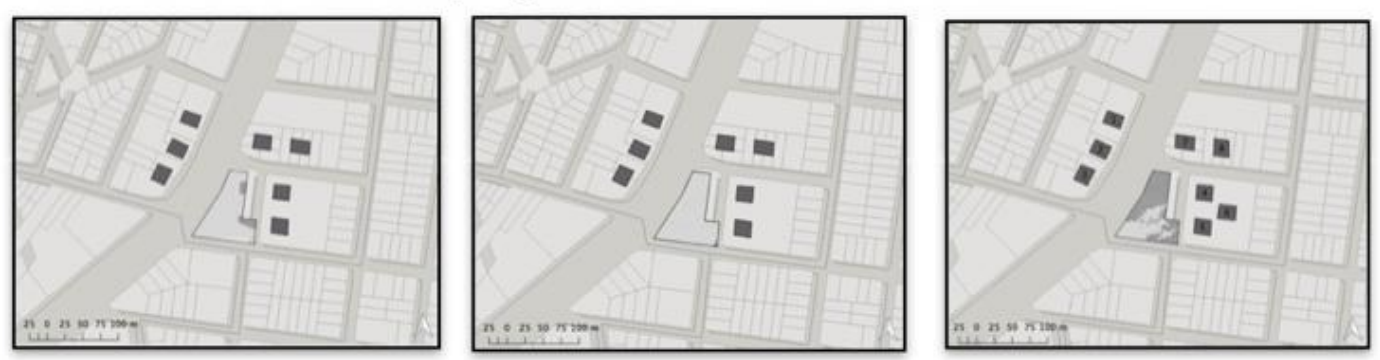

\section{Legenda}

Zoneamento de Sombras (Horas)

Até 3 horas de sombra

Entre 3 e 5 horas de sombra

Mais de 5 horas de sombra

Figura 12 - Comparação dos Mapas de Zoneamento de Sombras na Praça Cova da Iria - cenários atual, com Índice Básico e com aquisição de potencial construtivo - Solstício de verão (a) e Equinócio de Primavera (b), Solstício de inverno (c). Fonte: Pinto (2019).

\section{Análise Geral}

De um modo geral, nas análises realizadas nos três espaços públicos selecionados, pôde-se observar que quando aplicado o índice da legislação com aquisição de potencial construtivo e, assim, gerando um aumento significativo na altura das edificações no entorno, principalmente no solstício de inverno, o impacto de sombreamento seria até $62 \%$ maior do que quando simulado com a configuração espacial atual, inclusive, com um maior número de horas de sombreamento.

As praças analisadas, que possuem diferentes dimensões, apresentaram resultados mais amenos em relação ao impacto de sombreamento quando considerada a configuração de entorno atual. Tanto o centro Esportivo Arnaldo Busato, quanto a Praça Cova da Iria apresentaram a totalidade de sua área sombreada por menos de três horas no solstício de inverno. Já a Praça da Ucrânia, mesmo tendo um entorno caracterizado pela mescla de edificações com alturas diversificadas, também teve resultados que apresentaram que a maior parte de sua área ficaria sombreada por menos de três horas, na mesma data analisada. A média de área total com menos de três horas de sombreamento nas três praças foi de $96 \%$, que é equivalente a área total a Praça Cova da Iria.

Considerando o cenário com aquisição de potencial construtivo, todos os espaços analisados teriam resultados de sombreamento preocupantes para o tipo de clima de Curitiba. A Praça Cova da Iria e a Praça 
Ucrânia, teriam mais de metade de sua área atingida por um sombreamento entre três e cinco horas num cenário possível, ou seja mais de $3.000 \mathrm{~m}^{2}$ e $1.500 \mathrm{~m}^{2}$ respectivamente atingidos pelo sombreamento. Já o Centro Esportivo Arnaldo Busato 04, a praça de maior área total analisada teria metade de sua área, ou $5.326 \mathrm{~m}^{2}$, sombreada durante até três horas, e a outra metade da área, ou $4.928 \mathrm{~m}^{2}$, até cinco horas de sombreamento (Tabela 6 e Figura 13).

Tabela 6 - Comparação das áreas atingidas pelo sombreamento nos diferentes espaços com os dois cenários analisados

\begin{tabular}{|c|c|c|c|c|c|c|c|c|c|c|c|c|}
\hline \multirow{4}{*}{ Espaços Analisados } & \multicolumn{12}{|c|}{ Quantidade de horas de sombreamento } \\
\hline & \multicolumn{6}{|c|}{ Cenário com configuração de entorno atual } & \multicolumn{6}{|c|}{$\begin{array}{c}\text { Cenário com configuração de entorno com } \\
\text { aquisição de potencial construtivo }\end{array}$} \\
\hline & \multicolumn{2}{|c|}{ Menos de $3 \mathrm{~h}$} & \multicolumn{2}{|c|}{ De 3h a $5 h$} & \multicolumn{2}{|c|}{ Mais de $5 \mathrm{~h}$} & \multicolumn{2}{|c|}{ Menos de $3 \mathrm{~h}$} & \multicolumn{2}{|c|}{ De 3h a $5 h$} & \multicolumn{2}{|c|}{ Mais de $5 \mathrm{~h}$} \\
\hline & $m^{2}$ & $\%$ & $\mathrm{~m}^{2}$ & $\%$ & $\mathrm{~m}^{2}$ & $\%$ & $m^{2}$ & $\%$ & $\mathrm{~m}^{2}$ & $\%$ & $\mathrm{~m}^{2}$ & $\%$ \\
\hline Praça Ucrânia & 2.449 & 89 & 303 & 11 & 12 & 0,4 & 852 & 31 & 1.504 & 54 & 407 & 15 \\
\hline $\begin{array}{l}\text { Centro Esp. Arnaldo } \\
\text { Busato } 04\end{array}$ & 10.255 & 100 & 0 & 0 & 0 & 0 & 5.326 & 52 & 2.763 & 27 & 2.165 & 21 \\
\hline Praça Cova da Iria & 5.150 & 100 & 0 & 0 & 0 & 0 & 1.957 & 38 & 3.193 & 62 & 0 & 0 \\
\hline Média & 5.951 & 96,3 & 101 & 3,7 & 4 & 0,1 & 2.711 & 40 & 2.486 & 47,6 & 1.128 & 12 \\
\hline
\end{tabular}

Fonte: autores.

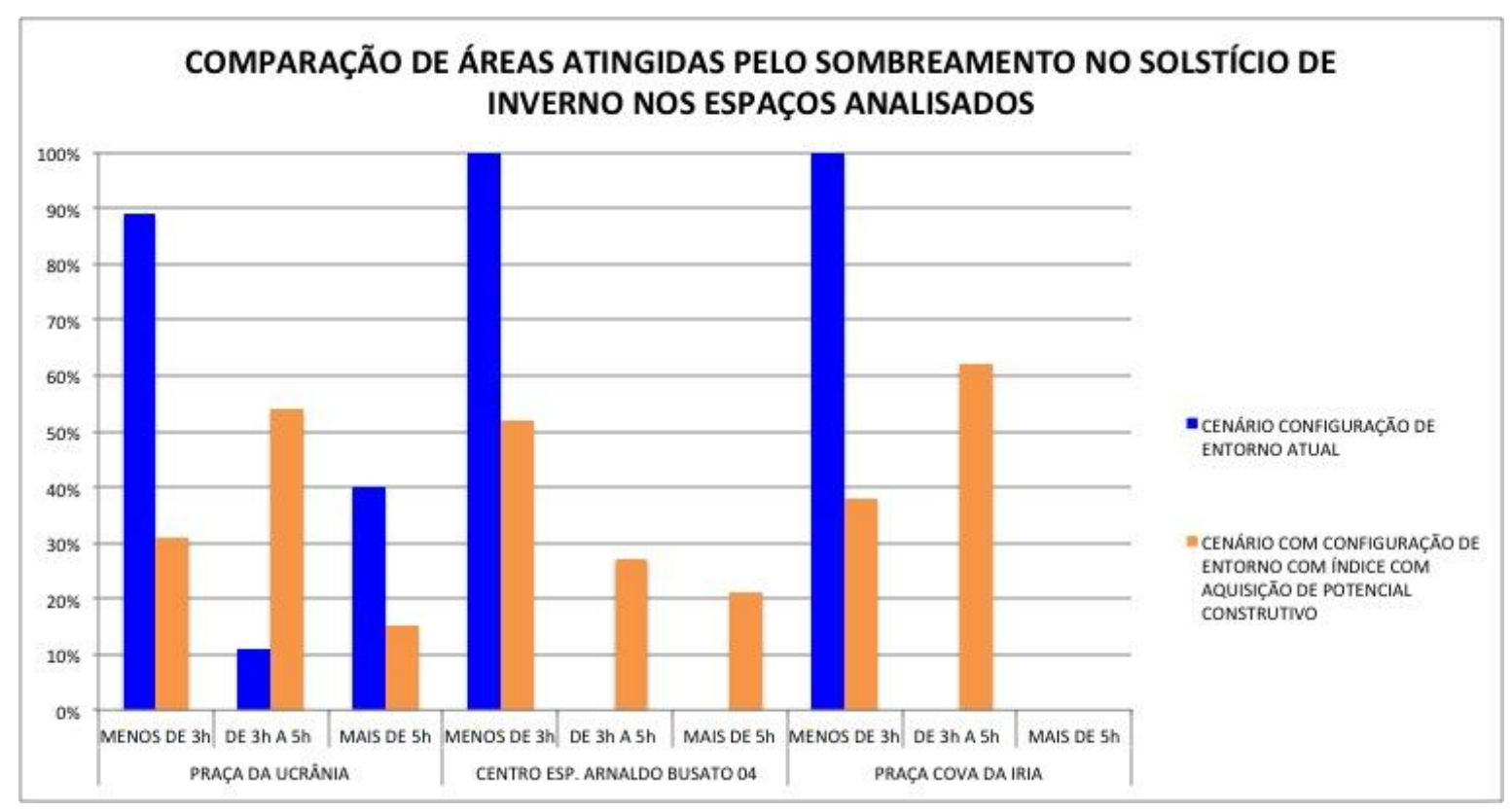

Figura 13 - Comparação das áreas atingidas pelo sombreamento nos diferentes espaços nos dois cenários analisados. Fonte: Adaptado de Pinto (2019).

\section{Conclusões}

A vitalidade de uma praça está diretamente ligada ao que pode oferecer a sua comunidade, observando a dinâmica social. Como se sabe, pessoas atraem pessoas. Mas a materialidade dos espaços públicos também são importantes mecanismos de atração de usuários. Apoiar-se nas condições climáticas, portanto, deveria ser um fator cada vez mais relevante para a configuração desse tipo de espaço público.

As praças escolhidas para análise nesse estudo estão localizadas em zonas não consolidadas ou em expansão no município de Curitiba/PR. Com as atualizações advinda do novo Plano Diretor Municipal, a partir de 2019, essas porções do território municipal poderiam passar por um processo de verticalização, que alteraria drasticamente a paisagem urbana atual. 
As análises de sombreamento realizadas nas três praças estudadas demonstram que a aquisição de potencial construtivo impacta ainda mais os espaços públicos, principalmente no solstício de inverno. Considerando-se Curitiba como um município caracterizado por clima frio no inverno, o acesso solar estaria comprometido. E se a cobertura vegetal existente nos espaços analisados fosse considerada no estudo, os resultados obtidos certamente seriam ainda mais expressivos.

Sendo assim, o estudo do impacto de sombreamento proveniente das edificações pode ser mais um componente de análise para delimitar as alturas das edificações no entorno de espaços públicos, sobretudo aqueles localizados em zonas em que se pretende ampliar os valores dos índices urbanísticos.

Juntamente ao desenvolvimento dos planos diretores e as leis urbanísticas e/ou ambientais, desde as federais até as municipais, deve haver ações de incentivo aos estudos ambientais impactantes no meio urbano, entre eles o estudo de sombreamento, já que têm como uma de suas finalidades ordenar o desenvolvimento urbano de forma equilibrada e sustentável, e também garantir o bem-estar de seus habitantes.

É preciso refletir com cuidado o quanto instrumentos de política urbana, como a outorga onerosa do direito de construir, a concessão para que a edificação seja construída acima dos limites estipulados na lei de zoneamento do município por meio de contrapartida financeira em favor do mesmo, ou a transferência de potencial construtivo, avaliando os impactos que poderiam se refletir nos espaços públicos existentes no entorno destas edificações, e talvez prejudicando a utilização destes espaços em várias épocas do ano.

\section{Referências}

Álvares, C. A., Stape, J. L., Sentelhas, P. C., DE Moraes Gonçalves, J. L., Sparovek G. (2013). Climate classification map for Brazil. Meteorologische Zeitschrift. Berlin, 22(6), 711-728.

Associação Brasileira De Normas Técnicas - ABNT. (2005). NBR 15220-3: Desempenho térmico de edificações - Parte 3 : Zoneamento bioclimático brasileiro e diretrizes construtivas para habitações unifamiliares de interesse social. Rio de Janeiro.

Bui, Q., \& White, J. (2017). The Struggle for Light and Air in America's Largest City. The New York Times. Recuperado em 10 de setembro de 2017, de https://www.nytimes.com/interactive/2016/12/21/upshot/Mapping-the-Shadows-of-NewYork-City.html?_r=0.

Bourbia, F., \& Awbi, H. B. (2004). Building cluster and shading in urban canyon for hot dry climate Part 1: Air and surface temperature measurements. Renewable Energy, 29, 249-262

Brasil (2001, 10 de Julho). Lei Federal n. 10.257, de 10 de julho de 2001. Estatuto da Cidade. Brasília: Diário Oficial da União.

Capeluto, I. G., Yezioro, A., Bleiberg, T. \& Shaviv, E. (2006). Solar rights in the design of urban squares. 23rd Conference on Passive and Low Energy Architecture -PLEA. Geneva. Switzerland. 6-8 September.

Castro Perez, D. R. (2013). Diretrizes Solares Para o Planejamento Urbano: o envelope solar como critério para adensamento e verticalização (Tese de Doutorado). Universidade Estadual de Campinas. Faculdade De Engenharia Civil, Arquitetura E Urbanismo. Campinas, São Paulo.

Correia Filho, W. L. F., Santiago, D. B., Oliveira-Júnior, J. F. \& Silva Junior, C. A. (2019). Impact of urban decadal advance on land use and land cover and surface temperature in the city of Maceió, Brazil. Land Use Policy, 87, 104026.

https://doi.org/10.1016/j.landusepol.2019.104026.

Costa, H. (2018). Criação de Ferramenta para Projeção de Sombreamento (Trabalho de Conclusão de Curso). Universidade Federal do Paraná (UFPR). Curitiba, Paraná.

Curitiba (2000, 03 de janeiro). Lei Municipal n. 9.800, de 03 de janeiro de 2000. Zoneamento, uso e ocupação do solo no Município de Curitiba.

Curitiba (2007). Plano Municipal de regularização fundiária em áreas de preservação permanente. Prefeitura Municipal de Curitiba.

Curitiba (2011, 19 de dezembro). Lei Municipal n. 13.909, de 19 de dezembro de 2011. Operação Urbana Consorciada Linha Verde no Município de Curitiba. 
Curitiba (2019, 10 de outubro). Lei Municipal n. 15511, de 10 de outubro de 2019. Zoneamento, uso e ocupação do solo no Município de Curitiba.

Curitiba (2020, 03 de julho). Lei Municipal n. 15661, de 06 de julho de 2020. Concessão de potencial construtivo adicional, mediante os instrumentos da Outorga Onerosa do Direito de Construir, Transferência do Direito de Construir e Cotas de Potencial Construtivo no Município de Curitiba. Diário Oficial Eletrônico nº 125.

Dorman, M., Vulkan, A., Erell, E., \& Kloog, I. (2017). Introduction to package shadow. Recuperado em 12 de Agosto de 2017 de https://cran.r-project.org/web/packages/shadow/vignettes/introduction.html.

Gehl, J. (2011). Life Between Buildings: Using Public Space (transl. by Koch, J.). New York: Van Nostrand Reinhold.

Gonçalves, R. M., Pacheco, A. P., Tanajura, E. L. X., \& Da Silva, L. M. (2013). Urbanização costeira e sombreamento na praia de Boa Viagem, Recife-PE, Brasil. Revista de Geografia Norte Grande, (54), 241-255.

Hoshino, T. A. P., Wütrich, F., Jacobovski, A., Faggion, A., Auler M. M., \& Becher, J. (2014). Do Estudo de Impacto de Vizinhança e de sua impostergável regulamentação e implementação no Município de Curitiba: análise comparativa e recomendações. Projeto Cidade em Debate. Nota Técnica. X Bienal del Coloquio de Transformaciones Territoriales "Desequilibrios regionales y políticas públicas. Una agenda pendiente". Córdoba, Argentina.

Huang, K., Lin, T., \& Lien, H. (2015). Investigating Thermal Comfort and User Behaviors in Outdoor Spaces: A Seasonal and Spatial Perspective. Hindawi Publishing Corporation. Advances in Meteorology. Article ID 423508. 2015.

Instituto Brasileiro de Geografia e Estatística - IBGE. (2010). Censo Demográfico 1940-2010. Recuperado em 02 dezembro de 2020, de https://seriesestatisticas.ibge.gov.br/series.aspx?vcodigo=POP122

Instituto De Pesquisa e Planejamento Urbano de Curitiba - IPPUC. (2019) Geodownloads - Dados Geográficos.

Leveratto, M. J. (2002). Urban planning instruments to improve winter solar access in open public spaces. Environmental Management and Health, 13(4), 366-372. https://doi.org/10.1108/09566160210439279.

Lin, T., Matzarakis, A., \& Hwang, R. (2010). Shading effect on long-term outdoor thermal comfort. Building and Environment, 45(1), 213-221.

Lin, T., Tsai, K. T., Liao, C. C., \& Huang, Y. C. (2013). Effects of thermal comfort and adaptation on park attendance regarding different shading levels and activity types. Building and Environment, 59, 599e611.

Lodoba, C. R., \& De Angelis, B. L. D. (2005). Áreas verdes públicas urbanas: conceitos, usos e funções. Revista Ambiência $1(1), 125-139$.

MACEDO, S. S. (1995). Espaços Livres. Paisagem e Ambiente: Ensaios, n. 7. São Paulo.

Martinelli, L., Lin, T., \& Matzarakis, A. (2015). Assessment of the influence of daily shadings pattern on human thermal comfort and attendance in Rome during summer period. Building and Environment, 92, 30e38.

Martins, J. C. (2019). Curitiba pode ter potencial construtivo adicional ao básico. Câmara Municipal de Curitiba. Notícias do Legislativo. Recuperado em 02 de junho de 2019, de https://memoria.cmc.pr.gov.br/ass_det.php?not=30545

Mendes, F. H., Silva Filho, D. F., \& Lopes, A. M. S. (2015). A sombra de edifícios como índice de verticalização das cidades. Hipótese, 1(1), 24-34.

Miranda, F., Doraiswamy, H., Lage, F., Wilson, L., Hsieh, M., \& Silva, C. T. (2017). Shadow Accrual Maps: Efficient Accumulation of City-Scale Shadows over Time. IEEE transactions on visualization and computer graphics, $\mathrm{XX}(\mathrm{X})$.

Moro, J., Krüger, E., \& Camboim, S. (2019). Metodologia para análise e quantificação de sombreamento proveniente de edificações de entorno sobre espaços públicos abertos. In Anais do XV Encontro Nacional de Conforto no Ambiente Construído - Encac. João Pessoa.

Piaskowy, N. A., \& Krüger. E. (2016). Analysis of shading and usage of sun-lit areas in an urban square in a subtropical location. In Conference, Windsor Comfort, Making Cumberland, Relevant Use, Energy.

Piaskowy, N. A., \& Krüger. E. (2017). Impact of solar access on visitor's behavior in an urban square in a subtropical location. Edimburgo: PLEA.

Pinto, J. M. M. (2019). Método De Caracterização Do Sombreamento De Espaços Públicos Abertos Gerado Por Edificações No Entorno (Tese de Doutorado). Universidade Tecnológica Federal do Paraná, Engenharia Civil. Curitiba, Paraná. 
Ribeiro, C., Matos De Carvalhos, H., \& Santos, M. (2010). Metodologia para análise do sombreamento em centros urbanos. III Simpósio Brasileiro de Ciências Geodésicas e Tecnologias da Geoinformação. Recife/PE.

Ribeiro, N. V. O. (2019) A praça na cidade contemporânea: análise espacial em Curitiba-PR. (Dissertação de mestrado). Universidade Federal do Paraná Setor de Tecnologia, Programa de Pós-graduação em Planejamento Urbano, Curitiba.

Rosaneli, A. F. (org.). (2019). Olhares pelo Espaço Público. Curitiba: Editora UFPR.

Santos, J. C. M. O. (2015). Conheça a História dos Planos Diretores de Curitiba - Parte 1. CMC - Câmara Municipal de Curitiba Recuperado em 09 de abril de 2019, de http://www.cmc.pr.gov.br/ass_det.php?not=25680\#\&panel1-1.

Schvarsberg, B., Martins, G. C., \& Cavalcanti, C. B. (2016). Estudo de Impacto de Vizinhança: Caderno Técnico de Regulamentação e Implementação. Brasília: Universidade de Brasília.

Schmitz, L. K., \& Mendonça, F. (2011). Reestruturação urbana e conforto térmico: cenários de modelização em Curitiba - PR após a copa de 2014. Revista Brasileira de Climatologia, 7(8), 61-81.

Topalov, C., Bresciani, S., Lille, L. C., \& D’arc, H.R. (orgs.). (2014). A Aventura das palavras da cidade, através dos tempos, das línguas e das sociedades. São Paulo: Romano Guerra.

Waldron, J. A., \& Salazar, J. H. (2013). Calculation of areas of permanence in public spaces, according to solar radiation simulated conditions. In Marcus, A. (Ed.): DUXU/HCII, Part III, LNCS 8014. (p. 215-223). Verlag Berlin Heidelberg: Springer.

WalL, E., \& Waterman, T. (2012). Desenho Urbano. Ed. Bookman. Porto Alegre.

Yezioro, A., \& Shaviv, E. (1994). Shading: A design tool for analyzing mutual shading between buildings. Solar Energy, 52(1), 27-37.

Yezioro, A., Capeluto, I. G., \& Shaviv, E. (2006). Design guidelines for appropriate insolation of urban squares. Renewable Energy, 31.

\section{Editor: Fábio Duarte}

Recebido: 29 out. 2020

Aprovado: 21 abr. 2021 